\title{
Visit to the Gaza Community Mental Health Programme: training in child mental health
}

\author{
Abdel Aziz Thabet and Panos Vostanis
}

The high prevalence of post-traumatic and other psychiatric disorders in children and adults who have experienced violence and war-related traumas are well documented by research (Thabet $\&$ Vostanis, 1998, 1999). So far, there has been less systematic evaluation of treatment interventions or training programmes for staff working with traumatised individuals in war zones. Training initiatives have recently been described in countries such as Rwanda (Brandon, 1998). This paper describes the work of a community mental health programme in the Gaza strip, particularly through a visit by $\mathrm{P}$. V. to work with the child mental health care staff.

\section{The Gaza strip}

The Gaza strip is an elongated area along the Mediterranean sea, between Israel and Egypt, covering $360 \mathrm{~km}^{2}$. It is overcrowded, with a population of about 860000 (approximately 2300 inhabitants per $\mathrm{km}^{2}$ ). Refugees make up $63 \%$ of the total population, while $51 \%$ are under 15 years of age. The Gaza strip is divided in five districts: North Gaza, Gaza city, Mid-zone, Khan Younis and Rafah.

\section{The Gaza Community Mental Health Programme (GCMHP)}

The Programme was established in 1990 to meet the mental health needs of the population following long-standing external conflict in the region, as well as internal social upheaval and economic deprivation (current unemployment rate of up to $70 \%$; Thabet $\&$ Vostanis, 1998). It is being funded by a number of international organisations (e.g. Amnesty International, United Nations Fund for Human Rights, Médecins Sans Frontières) and charitable bodies in Europe and North America. The GCMHP provides a general community mental health service and specialist provision for the more vulnerable societal groups (i.e. traumatised children, women who have suffered domestic violence, other victims of human rights abuse and people who misuse drugs). In addition to clinical work, there are training activities for the staff (workshops, study days, seminars, courses) and ongoing research. In 1997, a two-year multidisciplinary postgraduate diploma course in Community Mental Health was developed.

Of the 70 staff of the GCMHP (including secretarial and other administrative staff), there are 11 clinicians working with children and their families (one psychiatrist, six psychologists, one general practitioner, one nurse and two social workers). About 1200 new service users are referred annually, $45 \%$ of whom are children (500 new cases) and $72 \%$ are refugees. The male: female ratio reflects the general population (55:45). The majority of families are self-referred (65\%) (Gaza Community Mental Health Programme, 1996/97). The whole range of psychosocial and pharmacological treatment modalities are being provided, and there is liaison with local schools.

\section{Objectives of the training visit}

The GCMHP has close links with a number of university departments in the UK and other Western countries, with representatives on the advisory board. The aims of this visit were to review and plan research and training collaboration, to discuss the direction of the child mental health service, and to organise intensive seminars for the staff.

\section{Seminars with the multi-disciplinary child mental health team}

This was a cohesive and fairly experienced group of professionals who, despite working with children and families at the time, originated from the adult mental health service. Their primary requirement was to translate a child mental health structured approach to assessment and treatment to their own training, patient and service needs. As one member of staff put it, "We want your experience with children, not your 
knowledge". Cultural aspects were obviously essential, but not as prominent or inhibiting as one might expect. The framework was therefore to follow a traditional format on "interviewing and treating children and families with mental health problems", with continuous exchange of case material at the end of each section.

For example, the presentation of the frequently anxiety-provoking assessment of suicidal risk was followed by UK-based case vignettes (the similarities between Asian and Arab extended families were useful to the trainer). The staff were immediately invited to recall their own case material. This was the only way of constantly checking the overlap and differences between two distant clinical settings and their service user groups. In the example of self-harm assessment, there was an immediate split within the training group on whether it was relevant to their service users. Some clearly interpreted behaviours as self-harming, others dismissed them as accidental. Although the intent of certain beha. viours is often difficult to interpret, on this occasion staff were encouraged to explore with the patient statements such as, "I want to go to heaven" (i.e. to distinguish as far as possible between religious beliefs and suicidal thoughts).

\section{Khan Younis clinic}

The outreach clinic serves a population of 250000 living in towns, villages and refugee camps in the southern part, down to the border with Egypt. We attended the team meeting and out-patient appointments, and discussed case management with the staff. The child case-load was broad, including somatising, emotional (particularly post-traumatic stress) and oppositional disorders, enuresis, learning disability and child protection issues. The clinic had excellent facilities, for example one-way mirror and play therapy material.

An example of a typical case scenario was of a child who developed post-traumatic stress disorder (nightmares, recurrent thoughts, avoidance) and stammering after witnessing a sibling being accidentally injured by a car. The child's symptoms had almost resolved following brief play therapy and behavioural work with the parents. Another familiar scenario concerned a patient with a long history of recurrent depressive episodes. The patient had been blinded by tear gas 10 years earlier, and was being treated with antidepressants and supportive psychotherapy. The patient's sensory and emotional state was described as being "blind outside and blind inside".

We returned to Gaza city past Palestinian villages and Israeli settlements, with school children of both communities enjoying playtime at their respective schools. The buzzing noise from both playgrounds was the same as from any other playground in the world.

\section{Jabalyia clinic}

The second outreach clinic covers North Gaza (population of 200000 ), also a mixture of towns, villages and refugee camps. It includes an occupational therapy department for people with chronic mental illness. The staff described their main difficulty as engaging the local community because of the stigma attached to mental illness. Also, the extreme deprivation and the parallel involvement of United Nations clinics has raised patients' expectations from the staff to find them employment, and to improve their limited residences and local standards of hygiene.

One case discussed concerned a child who had become mute two years earlier (early language development had been normal). More recently, the child had recovered some language capacity (i.e. a presentation of elective mutism within the family environment). It transpired that the child had initially suffered from a specific phobia of the dark, but the anxiety symptoms had increased, mediated by the family response (anxiety and overprotection from the parents and teasing by siblings). The child responded well to behavioural management with the parents, which aimed at re-establishing a normal pattern in the child's life.

The team meeting and supervision was followed by a home visit in the refugee camps. About 100000 people live in an area of only $9 \mathrm{~km}^{2}$, with very poor standards and limited employment opportunities. We saw a family with eight children. The team had been involved for years, mainly with the father who had a long history of depression and social withdrawal. At different times they had seen five of the children because of bed-wetting, aggressive behaviour and emotional problems. As we were talking to the parents, one of the children watched anxiously. We invited the child in and explored their feelings. The child was worried about the father being unwell and not having a job, and about the parents arguing. The father gave the child a warm look and a gentle telling off. The parents then started an argument about their poor finances.

\section{Further challenges}

The services provided by the GCMHP are innovative and of high clinical standard, under extremely adverse circumstances. The Programme will gradually need to move in a strategic way from a number of separately funded initiatives to an established and cohesive 
mainstream service. Financial stability, training autonomy and ongoing service evaluation will be essential through this transition. Also, the Programme should continuously adapt to the substantial political and societal changes, and their impact on the population. Such emerging service and training models can provide useful learning experience to staff from both 'developing' and 'developed' mental health care systems, as there are strong similarities in work with traumatised children and families across societies.

\section{Acknowledgements}

We are grateful to the staff of the Gaza Community Mental Health Programme for their hospitality, and to all funding organisations for supporting the GCMHP.

\section{References}

Brandon, S. (1998) Note from Rwanda. Psychiatric Bulletin. 22, 50-51.

Gaza Community mental Health Programme (1996/97) Gaza Community Mental Health Programme. Gaza: Printing House of the Benevolent Society.

ThaBet, A. A. \& VostanIS, P. (1998) Social adversities and anxiety disorders in the Gaza strip. Archives of Disease in Childhood, 78, 439-442.

$-\&-(1999)$ Post-traumatic stress reactions in children of war. Journal of Child Psychology and Psychiatry, 40. 385-392.

Abdel Aziz Thabet, Projects Officer, Gaza Community Mental Health Programme, Gaza; and Panos Vostanis, Professor of Child and Adolescent Psychiatry, University of Leicester, Greenwood Institute of Child Health, Westcotes House, Westcotes Road, Leicester LE3 OQU

*Correspondence

\section{Ethnicity: An Agenda for Mental Health \\ Edited by Dinesh Bhugra}

This book sets the scene for identifying and meeting the mental health needs of black and minority ethnic groups. Clinicians, researchers, academics, hospital managers, commissioners and voluntary organisation workers come together to discuss the problems in health care delivery and the way of moving the agenda forward. In addition to multidisciplinary working, the key emphasis here is in involving commissioners and voluntary organisations in deciding how best to meet the needs of the communities. It will be of interest to all mental health professionals including psychiatrists, trainees, nurses, occupational therapists, psychologists, social workers and health care managers.

May 1999, 240pp, Paperback, ISBN 1901242 15 3, £25.00

Available from Book Sales, Royal College of Psychiatrists, 17 Belgrave Square, London SW1X 8PG

Tel +44 (0) 1712352351 (extension 146), Fax +44 (0) 1712451231

http://www.rcpsych.ac.uk 